\title{
Knowledge, attitude and barriers regarding smoking cessation counseling among primary health care physicians in Jeddah, 2019
}

\author{
Ahmed Mohammed Alrufaidy ${ }^{*}$, Osama Alsubhi ${ }^{2}$, Rabea Khalifa ${ }^{3}$, Marwan Abdulrhman Bakarman ${ }^{4}$ \\ 1-3Family Resident, ${ }^{4}$ Associate Professor, Dept. of Family and Community Medicine, ${ }^{1-3}$ The Joint Program of Family Medicine, \\ Ministry of Health Jeddah, Saudi Arabia, ${ }^{4}$ Faculty of Medicine, King Abdul Aziz University, Jeddah, Saudi Arabia
}

\section{*Corresponding Author: Ahmed Alrufaidy}

Email: a.alrufaidy@gmail.com

\begin{abstract}
Background: Tobacco smoking is highly prevalent in Saudi Arabia, and there is a need to reduce the resultant health burden via patient-oriented smoking cessation interventions. Primary care physicians (PCPs) have a significant role in providing counselling and advice to quit smoking.

Objectives: To assess knowledge and attitudes of PCPs regarding smoking cessation counselling (SCC) and to investigate the barriers and facilitators to providing SCC care.

Methods: A cross-sectional study was conducted including family physicians, general practitioners (GPs), and dentists working at primary healthcare centers (PHCCs) in Jeddah, Saudi Arabia. The included PHCCs were selected via a random sampling technique, and all eligible PCPs were approached via a semi-structured, self-administered questionnaire comprising of 33 items.

Results: A total of 130 physicians responded (55.4\% females, 60.2\% family physicians, 16.2\% smokers). The median (P75) knowledge score was 5.00 (6.00) out of 10, and 36.2\% of the participants had adequate knowledge. Significantly higher knowledge levels were reported among family physicians and GPs compared to dentists $(\mathrm{p}=0.004)$, as well as PCPs who received training on SCC $(p=0.001)$ and those with better confidence in providing interventions $(p=0.005)$. The majority of PCPs acknowledged the importance of SCC interventions $(96.2 \%)$ and necessity to provide regular advice $(90.8 \%)$. The lack of time to provide advice and follow-up were significant barriers, while being involved in SCC was reported as the main facilitator.

Conclusion: There is an urgent need to promote PCPs' knowledge via suitable solutions, such as continuing medical education on SCC, digital education interventions, and specialized SCC centers.
\end{abstract}

Keywords: Smoking Cessation, Primary Health Care, Counseling, Health Knowledge, Attitudes, Practice.

\section{Introduction}

Tobacco smoking has risen to become one of the major problems globally. This poses serious challenges and negatively effects many sectors, mainly healthcare.

According to the World Health Organization (WHO), smoking is one of the biggest public health threats in the world, responsible for more than 7 million deaths per year. It accounts for one in ten deaths among adults and represents the main cause of premature death globally. ${ }^{1} \mathrm{On}$ average, smokers die ten years earlier than nonsmokers. ${ }^{2}$

In Saudi Arabia, among the population aged 15 or more, approximately $37.6 \%$ of males and $6 \%$ of females are current smokers. ${ }^{3}$ The social, health and economic burden of tobacco use in Saudi Arabia is estimated to be five billion Riyals per year (1.3 billion US\$). ${ }^{4}$

Tobacco smoking is considered a major risk factor for the development of many non-communicable diseases, ${ }^{5}$ such as cardiovascular diseases, chronic obstructive pulmonary disease, lung cancer and other types of cancer, which represent the most frequent smoking related causes of death. ${ }^{2}$ Consequently, effective national strategies for smoking cessation constitute a crucial measure for the prevention of such lethal diseases and their morbidity.

One approach is the promotion of smoking cessation counseling through authoritative figures, such as primary healthcare centers' physicians. Being exposed to a large proportion of the population, general practitioners working in these primary healthcare centers could contribute to a considerable decrease in smoking rates, by targeting a significant number of smokers.

The United States Preventative Services Task Force (USPSTF) highly recommends "that clinicians screen all adults for tobacco use and provide tobacco cessation interventions for those who use tobacco products (Grade A recommendation). ${ }^{6}$ Other international studies demonstrate that the success rate of smoking cessation can be significantly improved by professional physician-led smoking cessation counseling combined to efficacious medication. ${ }^{7,8}$ Even a brief advice (five minutes or less) on smoking cessation can increase cessation rates. The 
USPSTF recommends that primary care physicians use the five A's (Ask, Advise, Assess, Assist, and Arrange) model when treating patients with nicotine addiction. ${ }^{6}$

In contrast, several human factors may constitute an obstacle to smoking cessation counseling, both from the counselors' and patients' sides, and may hinder the successful implementation of such prevention strategies. A study from the UK reported several physician-related barriers regarding smoking cessation counseling, such as; the lack of time during regular consultations, the lack of confidence from the physicians' part in discussing smoking with patients and the existence of knowledge gaps in regards to counseling. ${ }^{4}$ Therefore, exploring these dimensions of obstacles among primary healthcare physicians is a key element for a successful smoking cessation strategy at a national scale.

The study was conducted to provide insights into physician-related factors that may interfere with smoking cessation counseling and to improve its quality in Saudi Arabia, by focusing on the Ministry of Health (MOH) primary healthcare centers, as they constitute a major part of the Saudi healthcare system. The study explored the levels of knowledge and attitude regarding smoking cessation counseling among primary healthcare physicians, and analyzed the demographic and professional factors associated with inadequate knowledge. Furthermore, it highlighted the barriers that physicians face in routine practice, with regards to providing sustainable and effective smoking cessation counseling.

\section{Materials and Methods}

A cross-sectional study was carried out during the period between $1 \backslash 12 \backslash 2019$ and $31 \backslash 1 \backslash 2020$ in $\mathrm{MoH}$ primary healthcare centers (PHCCs) of Jeddah city, Saudi Arabia. Jeddah is the second-largest city in Saudi Arabia, and it contains four major supervisory healthcare sectors and 40 PHCCs reporting to the $\mathrm{MoH}$. The study population included primary care physicians (PCPs), including general practitioners (GPs), family physicians, and dentists, working at their respective medical institutions. The ethical approval of the study protocol was obtained from the Ministry Of Health in Saudi Arabia, Eligible physicians were voluntarily asked to participate, and their data were kept confidential and were only used for research purposes.

\section{Sampling}

In general, the total number of PCPs in Jeddah was estimated to be 200 across all MoH PHCCs. Sample size was calculated using the Raosoft online calculator ${ }^{9}$ based on a confidence interval of $95 \%$, margin of error of $5 \%$, and a response distribution of $50 \%$. Considering a $10 \%$ non-response rate, the total sample size was computed as 146 PCPs.

As for PHCC sampling, the average number of physicians per center was initially estimated, assuming an equal distribution of PCPs across all centers, by dividing the total number of physicians $(n=200)$ over the number of PHCCs $(n=40)$. This resulted in a mean of five PCPs per center. Consequently, the number of PHCCs to be sampled was calculated using the following formula: total sample size / average number of physicians per center (146/5), giving rise to 30 PHCCs. The included centers were selected using a random sampling technique via the online random number generator tool (www.random.org).

\section{Data collection}

Data collection tool was a semi-structured, selfadministered questionnaire, which had been adapted with permission from a previous cross-sectional study. ${ }^{10}$ The questionnaire includes a total of 33 items distributed across four major domains: 1) demographic, professional, and personal smoking-related data (11 items), such as age, gender, current professional position, current PHCC, receiving previous training on smoking cessation, number of smoking patients checked per week, the personal smoking status, as well as pattern (frequency) of smoking, previous quit attempts, the used cessation strategies, and the triggering factors of quitting, if any; 2) knowledge about smoking cessation, including sources of information regarding counselling ( 1 item), and a set of 12 items exploring knowledge level about the, the best pharmacologic and/or non-pharmacologic approaches to cessation, familiarity with and the importance of the 5A approach, and the efficacy and safety of multiple cessation strategies, such as nicotine replacement therapy, nicotine gum, nicotine patches, and bupropion; 3) attitude towards smoking cessation counseling ( 7 items), including the perceived importance of regular counselling and the discussion regarding smoking habits, providing advices to quit, and the personal satisfaction regarding personal knowledge and skills on counselling; 4) barriers and facilitators of smoking cessation counseling ( 2 items). Each eligible participant received a hard copy of the data 
collection tool and he/she was allowed to fill in data within 30 minutes.

\section{Statistical analysis}

Statistical analysis was performed with the Statistical Package for Social Sciences version 21.0 for Windows (SPSS Inc., Chicago, IL, USA). Descriptive statistics were carried out to present the participants' characteristics and patterns of their answers to the other questionnaire subscales including Knowledge, Sources of knowledge, Attitude, and Barriers \& encouraging measures. Knowledge score was calculated as the number of correct answers (range 0-12), and normality tests including Kolmogorov-Smirnov and Shapiro-Wilk tests were used to analyze the distribution of knowledge score variable in the study population. Adequate level of knowledge was defined as a knowledge score > median value, and the association of knowledge level with demographic and professional factors as well as with attitude towards smoking cessation counseling were analyzed by comparing the group of participants with adequate versus those with inadequate knowledge level, using independent t-test for continuous variables and chi-square or Fisher's exact test for categorical variables, as appropriate. A $p$ value of $<0.05$ was considered to reject the null hypothesis.

\section{Results}

Demographic, professional, and personal smokingrelated characteristics

Of a total 147 recollected questionnaire, 17 incompletely filled, resulting in a response rate $=88.4 \%$. Characteristics of the 130 participating physicians showed, mean (SD) age $=35.09$ (8.01) years, and $55.4 \%$ were females. Professionally, $24.6 \%$ were GPs, $60.2 \%$ were family physicians and $11.5 \%$ were dentists; while $6(4.6 \%)$ did not mention their position. Of the total participants, 21 $(16.2 \%)$ were smoker; and $30.8 \%$ see more than 10 smoker patients per day, and $61.5 \%$ declared having received training on smoking cessation techniques (Table 1).

\section{Smoking pattern and quitting among smoker physicians}

Focusing on the smoking physicians $(\mathrm{n}=21)$, smoking intensity was low to moderate in about half of the smokers (5-9 and < 5 cigarettes per day in $28.6 \%$ and $23.8 \%$, respectively). Interestingly, $52.4 \%$ of the smoking PCPs have previously tried to quit smoking, of them $45.5 \%$ have used medications. The main reason for quitting was primarily health-related $(72.7 \%)$, an increased cost of cigarettes (36.4), or the impact of warning labels (27.3\%, Table 2).

\section{Sources of information about smoking cessation counseling}

More than half of the respondents declared that they have obtained information regarding smoking cessation counselling from the postgraduate medical training $(53.8 \%)$ or the internet $(50.8 \%)$. Other notable sources included workshops and PHCC peers, as indicated by $42.3 \%$ and $37.7 \%$, respectively. On the other hand, published research articles and conferences represented minor roles, as these sources provided information to $27.7 \%$ and $31.5 \%$ of PCPs, respectively (Fig. 1).

\section{Assessment of knowledge about smoking cessation counseling}

Based on the responses provided by the participants, the highest percentage of correct answers were pertinent to the familiarity with the $5 \mathrm{~A}$ approach $(81.5 \%)$, perceptions regarding the optimal method of cessation with the best successful short- and long-term outcomes (76.2\%), and the medication-based strategy which is equally effective as sustained-release bupropion (56.9\%). Conversely, the least correct responses were provided to statements related to nicotine patches $(8.5 \%)$, nicotine gum $(13.8 \%)$, and the nicotine replacement system that offers the fastest delivery of the active substance (16.9\%, Fig. 2).

\section{Levels of knowledge and scale reliability}

The knowledge domain showed acceptable reliability as indicated by a Cronbach's alpha of 0.606 . For the analysis of overall knowledge scores, tests of normality indicated that data was non-normally distributed (KolmogorovSmirnov [0.123, $\mathrm{p}<0.001]$; Shapiro-Wilk [0.996, $\mathrm{p}=0.002])$. The median (P75) knowledge score was 5.00 (6.00) out of 12, whereas the mean (SD) value was 4.71 (2.11). Considering the median score as a cutoff value for adequate knowledge, only $36.2 \%$ (95\% confidence interval $27.9 \%$ to $46.0 \%$ ) were regarded as adequately knowledgeable. The distribution of knowledge scores is depicted in Fig. 3. 


\section{Attitude towards smoking cessation counseling}

The highest rates of agreement (strongly agree or agree) were related to appreciating the importance of performing smoking cessation counselling (96.2\%), followed by providing regular advice to patients to quit smoking (90.8\%) and asking the patient about his/her smoking habits on a regular basis (86.2\%). Intriguingly, only $52.3 \%$ of the participants were satisfied regarding personal knowledge and skills on counselling, and only $46.2 \%$ of them thought that being an active smoker would be a barrier to advise patients to quit smoking (Table 3).

\section{Physician-perceived barrier and encouraging measures to smoking cessation counseling}

The most frequently perceived barriers to providing smoking cessation counselling were the lack of time during an appointment (82.3\%), inability to follow-up patients $(77.7 \%)$, and failed quit attempts $(71.5 \%)$. On the other hand, the most commonly reported encouraging measures were being involved in a smoking cessation program $(76.9 \%)$ and including the "tobacco status" label as a mandatory form in paper medical records $(71.5 \%$, Table 4).

\section{Factors associated with knowledge regarding cessation counselling}

Concerning demographic and professional factors, family physicians had the highest level of knowledge (44.2\% of adequate knowledge), followed by GPs (31.3\%), while $0 \%$ of dentists had and adequate knowledge, and the comparison was statistically significant $(\mathrm{p}=0.004)$. Further, knowledge level was higher among physicians who declared having received a training on smoking cessation techniques (adequacy rate $=47.5 \%$ versus $18.0 \%$ ) compared to their counterparts, respectively. No association of knowledge level was found with the physician's age $(p=0.271)$, gender $(p=0.276)$, smoking status $(\mathrm{p}=0.769)$ or daily patient flow $(\mathrm{p}=0.650)$ (Table $5)$.

As for participants' attitudes, physicians who had adequate knowledge reported more confidence $(85.1 \%$ versus $61.3 \%, \mathrm{p}=0.005$ ), and were more frequently favorable to the necessity of routinely interviewing patients about smoking habits $(95.7 \%$ versus $83.8 \%$, $\mathrm{p}=0.049$ ) and to the efficacy of continuous advice in enhancing the chances of quitting $(93.6 \%$ versus $71.3 \%$, $\mathrm{p}=0.003$ ), compared to those who had inadequate knowledge, respectively (Table 6).

Table 1: Participants' demographics, smoking history and professional characteristics $(\mathrm{N}=130)$

\begin{tabular}{|l|c|c|c|}
\hline Parameter & Category & Frequency & Percentage \\
\hline Age & Mean, SD & 35.09 & 8.01 \\
\hline Gender & Male & 58 & 44.6 \\
\hline Position & Female & 72 & 55.4 \\
\hline & GP & 32 & 24.6 \\
\hline & Family Medicine Resident & 49 & 37.7 \\
\hline & Family Medicine Specialist & 23 & 17.7 \\
\hline & Family Medicine Consultant & 5 & 3.8 \\
\hline & Dentist & 15 & 11.5 \\
\hline Smoker & Missing & 6 & 4.6 \\
\hline & No & 109 & 83.8 \\
\hline \multirow{2}{*}{$\begin{array}{l}\text { Number of smoker patients } \\
\text { seen per day }\end{array}$} & Yes & 21 & 16.2 \\
\cline { 2 - 4 } & $<5$ & 30 & 23.1 \\
\cline { 2 - 4 } & $5-10$ & 48 & 36.9 \\
\cline { 2 - 4 } & $>10$ & 40 & 30.8 \\
\hline \multirow{2}{*}{$\begin{array}{l}\text { Ever received training on } \\
\text { smoking cessation techniques }\end{array}$} & Do not know & 12 & 9.2 \\
\cline { 2 - 4 } & Yes & 80 & 61.5 \\
\hline
\end{tabular}


Table 2: Smoking pattern and quitting among smoker physicians $(\mathrm{N}=21)$

\begin{tabular}{|l|c|c|c|}
\hline Parameter & Category & Frequency & Percentage \\
\hline No. cigarettes per day & $<5$ & 5 & 23.8 \\
\hline & $5-9$ & 6 & 28.6 \\
\hline & $10-14$ & 4 & 19.0 \\
\hline & $15-24$ & 4 & 19.0 \\
\hline Previous quit trials & Not mentioned & 2 & 9.5 \\
\hline & No & 10 & 47.6 \\
\hline Medication used & Yes & 11 & 52.4 \\
\hline & No & 5 & 54.5 \\
\hline & Yes & 4 & 45.5 \\
\hline & Champix & 1 & 36.4 \\
\hline Reasons for quitting & Not specified & 8 & 9.1 \\
\hline & Health concern & 2 & 9.1 \\
\hline & Secondhand smoke concern & 1 & 18.2 \\
\hline & Family disapproval & 4 & 9.1 \\
\hline & Smoking ban / restrictions & 3 & 36.4 \\
\hline & Price & 27.3 \\
\hline
\end{tabular}

Table 3: Attitude towards smoking cessation counseling $(\mathrm{N}=130)$

\begin{tabular}{|l|c|c|c|c|c|c|c|}
\hline \multirow{2}{*}{ Attitude } & \multicolumn{5}{|c|}{ Level of agreement, N (\%) } & Mean \\
\cline { 2 - 7 } & $\begin{array}{c}\text { Strongly } \\
\text { agree }\end{array}$ & Agree & Neural & Disagree & $\begin{array}{c}\text { Strongly } \\
\text { disagree }\end{array}$ & $\begin{array}{c}\text { \% } \\
\text { Agree }\end{array}$ & \\
\hline $\begin{array}{l}\text { Performing fmoking } \\
\text { cessation counseling for my } \\
\text { patients is important. }\end{array}$ & $98(75.4)$ & $27(20.8)$ & $2(1.5)$ & $0(0.0)$ & $0(0.0)$ & 96.2 & 1.24 \\
\hline $\begin{array}{l}\text { I feel confident in my } \\
\text { abilities to perform smoking } \\
\text { cessation counseling for my } \\
\text { patients. }\end{array}$ & $44(33.8)$ & $45(34.6)$ & $29(22.3)$ & $9(6.9)$ & $0(0.0)$ & 68.5 & 2.02 \\
\hline $\begin{array}{l}\text { I should routinely ask about } \\
\text { my patients' smoking habits. }\end{array}$ & $64(49.2)$ & $48(36.9)$ & $14(10.8)$ & $1(0.8)$ & $0(0.0)$ & 86.2 & 1.62 \\
\hline $\begin{array}{l}\text { I should routinely advise my } \\
\text { patients to quit smoking. }\end{array}$ & $76(58.5)$ & $42(32.3)$ & $8(6.2)$ & $1(0.8)$ & $0(0.0)$ & 90.8 & 1.48 \\
\hline $\begin{array}{l}\text { If I advise my patients to quit } \\
\text { continuously, their chances } \\
\text { of quitting smoking are } \\
\text { increased. }\end{array}$ & $53(40.8)$ & $48(36.9)$ & $24(18.5)$ & $2(1.5)$ & $0(0.0)$ & 77.7 & 1.8 \\
\hline $\begin{array}{l}\text { If I was an active smoker, I } \\
\text { would be less likely to advise } \\
\text { my patients to stop smoking. }\end{array}$ & $29(22.3)$ & $31(23.8)$ & $19(14.6)$ & $20(15.4)$ & $27(20.8)$ & 46.2 & 2.88 \\
\hline $\begin{array}{l}\text { I am satisfied regarding my } \\
\text { knowledge and skills on } \\
\text { smoking cessation } \\
\text { counseling. }\end{array}$ & $28(21.5)$ & $40(30.8)$ & $38(29.2)$ & $16(12.3)$ & $4(3.1)$ & 52.3 & 2.43 \\
\hline
\end{tabular}


Table 4: Physician-perceived barriers and encouraging measures to smoking cessation counseling

\begin{tabular}{|l|c|c|}
\hline Barrier & $\mathbf{N}$ & \% \\
\hline Lack of training & 88 & 67.7 \\
\hline Lack of time & 107 & 82.3 \\
\hline Failure to follow up patients & 101 & 77.7 \\
\hline Frequent relapse and withdrawal symptoms & 90 & 69.2 \\
\hline Patients' resistance to change & 93 & 71.5 \\
\hline Other obstacles & 2 & 1.6 \\
\hline Encouraging measure & & \\
\hline Add tobacco status as a mandatory item in electronic medical records & 72 & 55.4 \\
\hline Add tobacco status as a vital sign in electronic medical records & 59 & 45.4 \\
\hline Add tobacco status as mandatory form in paper medical records & 93 & 71.5 \\
\hline Add tobacco status as a vital sign in paper medical records & 91 & 70.0 \\
\hline Be involved in smoking cessation program & 100 & 76.9 \\
\hline
\end{tabular}

Table 5: Factors associated with knowledge about smoking cessation counseling $(\mathrm{N}=130)$

\begin{tabular}{|c|c|c|c|c|c|c|}
\hline \multirow[t]{3}{*}{ Factor } & \multirow[t]{3}{*}{ Category } & \multicolumn{4}{|c|}{ Knowledge level } & \multirow[t]{3}{*}{ p-value } \\
\hline & & \multicolumn{2}{|c|}{ Adequate } & \multicolumn{2}{|c|}{ Inadequate } & \\
\hline & & $\mathbf{N}$ & $\%$ & $\mathbf{N}$ & $\%$ & \\
\hline Age & Mean, SD & 33.98 & 7.38 & 35.69 & 8.32 & .271 \\
\hline \multirow[t]{2}{*}{ Gender } & Male & 18 & 31.0 & 40 & 69.0 & \\
\hline & Female & 29 & 40.3 & 43 & 59.7 & .276 \\
\hline \multirow[t]{5}{*}{ Position } & GP & 10 & 31.3 & 22 & 68.8 & \\
\hline & FM Resident & 24 & 49.0 & 25 & 51.0 & \\
\hline & FM Specialist & 7 & 30.4 & 16 & 69.6 & \\
\hline & FM Consultant & 3 & 60.0 & 2 & 40.0 & \\
\hline & Dentist & 0 & 0.0 & 15 & 100.0 & $.007 *$ \\
\hline \multirow{3}{*}{$\begin{array}{l}\text { Position } \\
\text { categories })\end{array}$} & GP & 10 & 31.3 & 22 & 68.8 & \\
\hline & Family physician & 34 & 44.2 & 43 & 55.8 & \\
\hline & Dentist & 0 & 0.0 & 15 & 100.0 & $.004 *$ \\
\hline \multirow[t]{2}{*}{ Smoker } & No & 7 & 33.3 & 14 & 66.7 & \\
\hline & Yes & 40 & 36.7 & 69 & 63.3 & .769 \\
\hline \multirow{4}{*}{$\begin{array}{l}\text { Number of smoker } \\
\text { patients seen per day }\end{array}$} & $<5$ & 9 & 30.0 & 21 & 70.0 & \\
\hline & $5-10$ & 19 & 39.6 & 29 & 60.4 & \\
\hline & $>10$ & 16 & 40.0 & 24 & 60.0 & \\
\hline & Do not know & 3 & 25.0 & 9 & 75.0 & .650 \\
\hline \multirow{2}{*}{$\begin{array}{l}\text { Received training on } \\
\text { smoking cessation } \\
\text { techniques }\end{array}$} & Yes & 38 & 47.5 & 42 & 52.5 & \\
\hline & No & 9 & 18.0 & 41 & 82.0 & $.001 *$ \\
\hline
\end{tabular}

Percentages are calculated among factors categories (row). SD: Standard deviation, GP: general practitioner, FM: family medicine, *statistically significant result $(\mathrm{p}<0.050)$. 
Table 6: Association of knowledge level with attitude regarding smoking cessation counseling $(\mathrm{N}=130)$

\begin{tabular}{|c|c|c|c|c|c|c|}
\hline \multirow[t]{3}{*}{ Dimension } & \multirow[t]{3}{*}{ Attitude } & \multicolumn{4}{|c|}{ Knowledge level } & \multirow[t]{3}{*}{ p-value } \\
\hline & & \multicolumn{2}{|c|}{ Adequate } & \multicolumn{2}{|c|}{ Inadequate } & \\
\hline & & $\mathbf{N}$ & $\%$ & $\mathbf{N}$ & $\%$ & \\
\hline \multirow{2}{*}{$\begin{array}{l}\text { Importance of smoking } \\
\text { counseling }\end{array}$} & Neutral or disagree & 0 & 0.0 & 2 & 2.5 & \\
\hline & Agree & 47 & 100.0 & 78 & 97.5 & $.530 \mathrm{~F}$ \\
\hline \multirow[t]{2}{*}{ Confidence in counseling } & Neutral or disagree & 7 & 14.9 & 31 & 38.8 & \\
\hline & Agree & 40 & 85.1 & 49 & 61.3 & $.005 *$ \\
\hline \multirow[t]{2}{*}{ Necessity of asking routinely } & Neutral or disagree & 2 & 4.3 & 13 & 16.3 & \\
\hline & Agree & 45 & 95.7 & 67 & 83.8 & $.049 * \mathrm{~F}$ \\
\hline \multirow[t]{2}{*}{ Necessity of advising routinely } & Neutral or disagree & 3 & 6.4 & 6 & 7.5 & \\
\hline & Agree & 44 & 93.6 & 74 & 92.5 & $1.000 \mathrm{~F}$ \\
\hline \multirow{2}{*}{$\begin{array}{l}\text { Efficacy of advising in } \\
\text { enhancing quit rate }\end{array}$} & Neutral or disagree & 3 & 6.4 & 23 & 28.8 & \\
\hline & Agree & 44 & 93.6 & 57 & 71.3 & $.003 *$ \\
\hline \multirow{2}{*}{$\begin{array}{l}\text { Physician's smoking reduces } \\
\text { likelihood of counseling }\end{array}$} & Neutral or disagree & 26 & 55.3 & 40 & 50.6 & \\
\hline & Agree & 21 & 44.7 & 39 & 49.4 & .611 \\
\hline \multirow{2}{*}{$\begin{array}{lll}\text { Satisfaction } & \text { about } & \text { own } \\
\text { knowledge } & & \end{array}$} & Neutral or disagree & 22 & 46.8 & 36 & 45.6 & \\
\hline & Agree & 25 & 53.2 & 43 & 54.4 & .893 \\
\hline
\end{tabular}

Percentage are calculated among column categories. ${ }^{*}$ Statistically significant result $(\mathrm{p}<0.050)$; ${ }^{\mathrm{F}}$ Fisher's exact test.

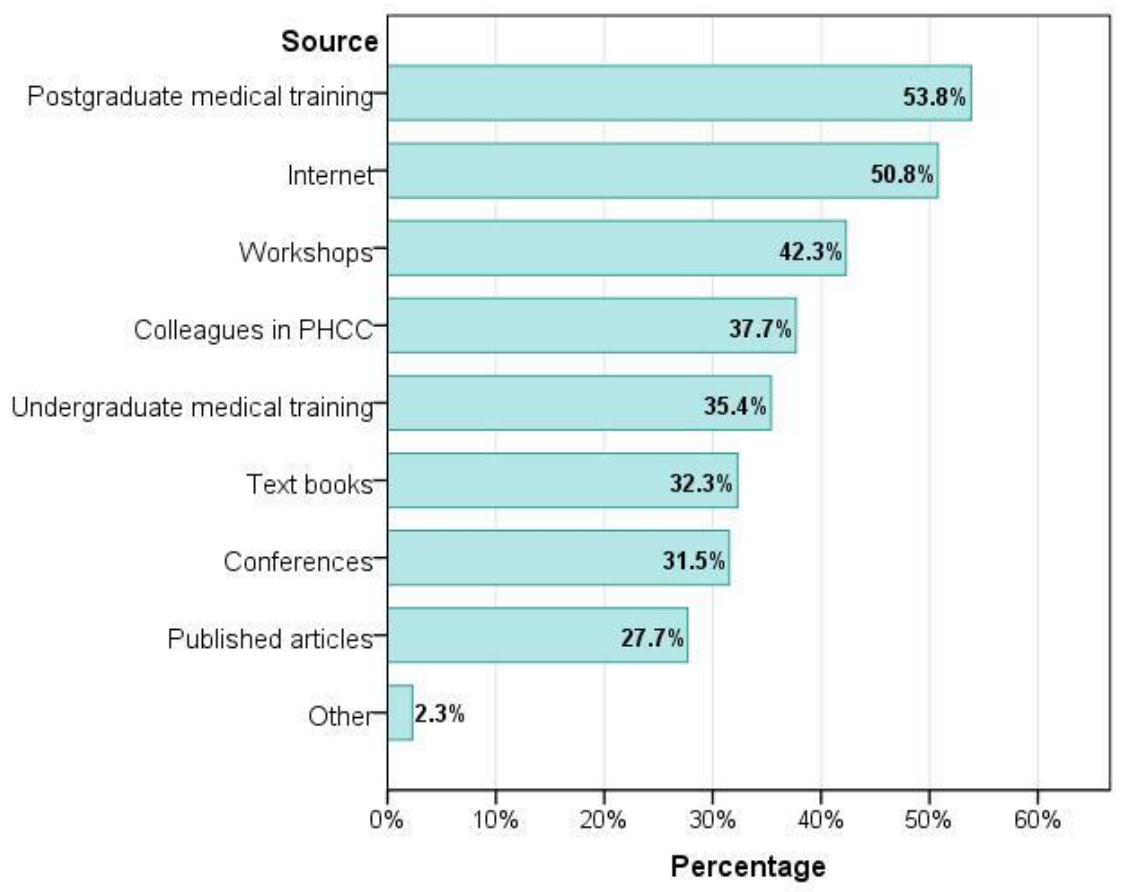

Fig. 1: Sources of information about smoking cessation counseling 


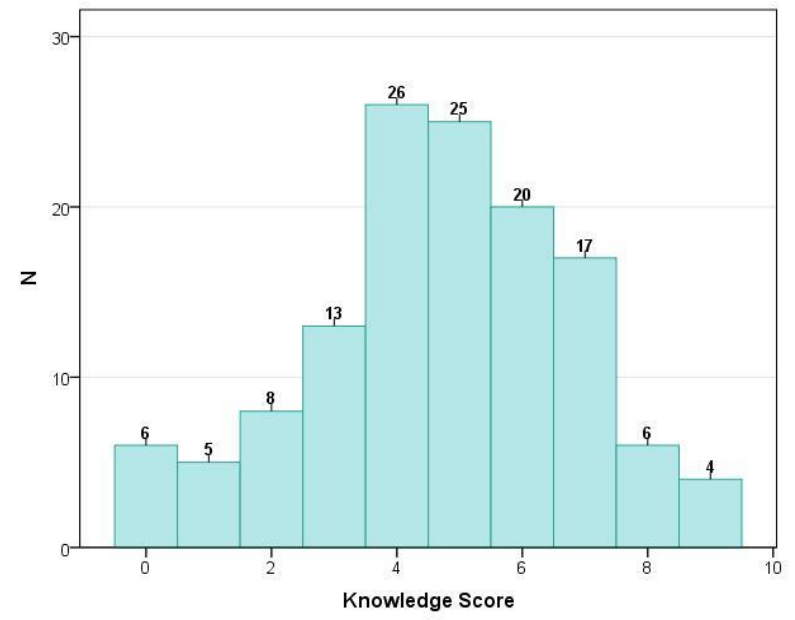

Fig. 2: Assessment of knowledge about smoking cessation counseling

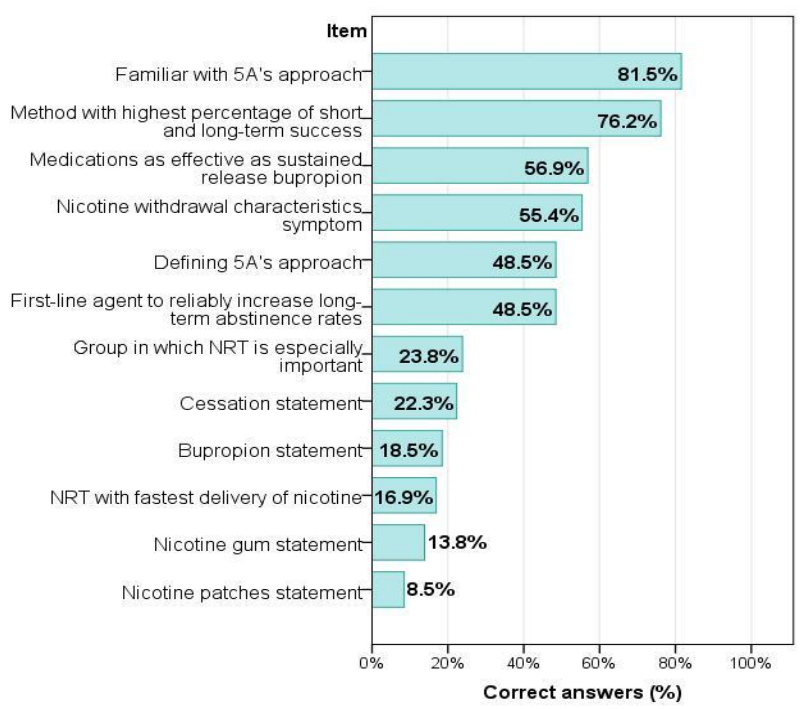

Fig. 3: Distribution of knowledge score

\section{Discussion}

The efficacy of smoking cessation is inevitably beneficial, and the cost-effectiveness of medical interventions for nicotine dependence have been well-established. ${ }^{11}$ Although physicians of different specialties may frequently ask their patients about their smoking statuses during examination, PCPs are expectedly more likely to contribute to providing advice and counselling regarding smoking cessation. Therefore, assessment of PCPs' knowledge and attitudes is a critical part of the smoking cessation interventions, which could reduce the burden of the resultant disorders in areas with high prevalence of smoking, such as Saudi Arabia. ${ }^{12,13}$ In the current crosssectional study, we showed that knowledge regarding abstinence counselling was moderate among Saudi PCPs, and $63.8 \%$ of them had inadequate knowledge levels. Knowledge levels were significantly higher among family physicians and GPs, those who had received a training on smoking cessation techniques, physicians with better confidence in counselling, and those having favorable attitudes towards the necessity of routine counselling. Besides, physicians' attitudes regarding the importance of cessation practices and providing regular advice to patients were mostly appreciated.

Actually, these findings indicate a significant shortage of the educational content on tobacco smoking in medical education. Undergraduate curricula in Saudi Arabia lack the required information regarding the risks of smoking and the need to motivating patients to abstinence. This was highlighted by Jradi and Al-Shehri, ${ }^{14}$ who showed that knowledge levels were generally low among students from three local medical schools, and the authors underscored the need to prioritize the topics related to smoking risks and treatment in medical education curricula. Similar patterns of low knowledge were reported among dental students regarding smoking as one of the most common risk factors of oral cancer. ${ }^{15-17}$ In our settings, improving the undergraduate dental curricula is necessary since dentists have shown the lowest levels of knowledge regarding counselling compared to other specialties.

Furthermore, it is imperative to establish regular training programs to enrich the knowledge of postgraduates, including PCPs. The impact of training on smoking cessation techniques was evident in the present study. Indeed, postgraduate medical training was the most acknowledged source of information, and trained PCPs $(61.5 \%)$ had higher knowledge scores than their untrained peers. In an early randomized clinical trial concerning the effect of an educational program on smoking cessation practices of internal medicine residents, ${ }^{18}$ trained subjects provided better counselling, and their patients exhibited higher motivation to quit and increased rates of cessation at one year of counselling. AlAteeq et al. ${ }^{19}$ have indicated that highly-educated and trained physicians in Riyadh were 17.9 times more likely to have positive attitude towards counselling and 9.5 times more likely to deliver regular advice to their patients compared to less-educated physicians. Similar outcomes were reported in PHCC centers in the Eastern Region. ${ }^{20}$ This way, scheduled training is advised to increase the knowledge and practice of PCPs. The need for such educative interventions has 
been repeatedly reported by more than half of family physicians in local and regional studies. ${ }^{10,19,21}$

As a consequence of the deficient educative materials, the internet and workshops were other common sources of information on smoking cessation practices in our study. Importantly, the internet was the main source of information among physicians and dentists in the National Guard Primary Healthcare Centers at the Western Region of Saudi Arabia. ${ }^{22}$ The internet is increasingly being utilized by health professionals in different niches as a reliable source of information, especially from authentic resources, such as the published academic articles and guidelines. $^{23,24}$ In a recent systematic review, digital education interventions, such as web-based, online courses, virtual reality platforms, or mobile learning, were all at least equally effective, or possibly more efficacious, as traditional learning approaches for health professionals to augment their anti-smoking knowledge and attitudes. ${ }^{25}$ In line with these findings, and with the progressively increasing application of technological interventions in our daily lives, health institutions and stakeholders are required to develop suitable online interventions aiming at promoting the basic smoking cessation literacy to PCPs.

Of note, smoking physicians represented about $16 \%$ of the current study sample, which is in agreement with other investigations in Egypt (16\%), ${ }^{21}$ Lebanon (14.3\%), ${ }^{26}$ the United Arab Emirates (12\%), ${ }^{27}$ and China (12.4\%), ${ }^{28}$ while it was lower than other studies conducted in Europe and Asia. ${ }^{29,30}$ The variation in demographic and cultural characteristics might have accounted for such differences. However, the impact of the smoking status as a barrier to smoking cessation practices was almost negligible as indicated by the participants in our study. While active smoker PCPs could still have the required skills to provide counselling, particularly with receiving regular training, patients' response to the advice of a smoking physician might be different. That is, nonsmoking physicians usually act as role models to the patient, setting a good example by refraining from smoking and thus can help in promoting cessation efforts. This way, smoker PCPs could be intensively targeted as to increase their personal knowledge regarding smoking risks as well as to encourage the need to provide effective counselling to the patients, considering their leading role.

In addition to the previously discussed interventions, it is necessary to mitigate the reported barriers and support the facilitators to deliver highly efficient smoking cessation practices. The lack of time was the most frequently reported barrier in the present analysis, followed by the failure to establish regular follow-up visits with patients and failed quit attempts. Likewise, in a study conducted in two academic centers in Riyadh, ${ }^{31}$ the major obstacles were the lack of time, lack of training, and the lack of interest in counselling by patients. The lack of time, which is consistently demonstrated as the primary barrier in Makkah, ${ }^{20}$ is possibly attributable to the fact that counselling needs too much time for guidance and discussion with patients. Once again, the employment of PCPs and dental professionals in anti-smoking programs as well as the regular involvement in continuing education training would promote their knowledge, increase their confidence during counselling, create more focused discussions with patients, and eventually reduce the time required during counselling. ${ }^{32}$ Alternatively, while family physicians can provide brief advice during visits as a part of their jobs, having special clinics and specific guidelines would motivate physicians to devote a significant amount of time to discuss the available methods and strategies of cessation. This can be considered by health authorities and academic committees, which can allocate specialized centers/clinics and create national guidelines for smoking cessation.

There are some limitations experienced in the present study. The self-report nature of the questionnaire made it difficult to exclude the response bias, particularly regarding the responses of smoking physicians. The prevalence of smoking among the participants might have been underreported because of the community's perceived image, which consider doctors as role models. Additionally, since we have implemented a crosssectional design, we were unable to determine cause and effect relationships, and thus the resultant associated factors with increased knowledge should be cautiously interpreted. Finally, the responses to distinct knowledge items, such as those pertinent to the 5A strategy, were subjectively assessed. The results of these items could not be reliable.

In conclusion, knowledge regarding smoking cessation counselling was moderate among PCPs and poor among dental professionals in Jeddah, Saudi Arabia. The impact of postgraduate training was evident ono enriching the knowledge, with trained physicians exhibiting better confidence, more favorable attitudes towards the necessity or routine discussion, and appreciating the efficacy of regular advice on enhancing the chances of quitting. Accordingly, it is recommended to enhance the personal 
knowledge of physicians either early through enriched undergraduate curricula or via implementing continuous education programs to PCPs. Moreover, health authorities and stakeholder should strive to develop digital education interventions to exploit the increased interest in internetbased resources and, from another perspective, should consider the establishment of specialized smoking cessation centers and national practice guidelines. These measures would ultimately increase knowledge levels of PCPs and mitigate the effect of barriers to smoking cessation practices by providing the required time for discussion and offering more productive and convenient environment for doctors and patients, respectively.

\section{Source of Funding}

None.

\section{Conflict of Interest}

None.

\section{References}

1. World Health Organization. WHO report on the global tobacco epidemic 2011 Geneva: WHO; 2011 [cited 2020 February 15]. Available from: https://www.who.int/tobacco/global_report/2011/en/.

2. Office of the Surgeon General. The Health Consequences of Smoking: A Report of the Surgeon General. Atlanta (GA): Centers for Disease Control and Prevention (US); 2004.

3. Fiore MC, Bailey WC, Cohen SJ, Dorfman SF, Goldstein MG, Gritz ER, et al. Treating tobacco use and dependence: clinical practice guideline. Rockville, MD: US Department of Health and Human Services, Public Health Service; 2000.

4. Vogt F, Hall S, Marteau TM. General practitioners' and family physicians' negative beliefs and attitudes towards discussing smoking cessation with patients: a systematic review. Addict. 2005;100:1423-31.

5. Verbiest M, Brakema E, van der Kleij R, Sheals K, Allistone G, Williams S, et al. National guidelines for smoking cessation in primary care: a literature review and evidence analysis. NPJ Prim Care Respir Med. 2017;27(1):2.

6. Siu AL, U. S. Preventive Services Task Force. Behavioral and pharmacotherapy interventions for tobacco smoking cessation in adults, including pregnant women: U.S. Preventive services task force recommendation statement. Ann Intern Med. 2015;163:622-34.

22. Al-Jdani S, Mashabi S, Alsaywid B, Zahrani A. Smoking cessation counseling: Knowledge, attitude and practices of primary healthcare providers at National Guard Primary Healthcare Centers, Western Region, Saudi Arabia. $J$ Family Community Med. 2018;25:175-82.

23. Oriogu CD, Subair RE, Oriogu-Ogbuiyi DC. Use of internet health information resources and information
7. Fiore M. Treating tobacco use and dependence: 2008 update: Clinical practice guideline: Diane Publishing; 2008.

8. Zhou C, Wu L, Liu Q, An H, Jiang B, Zuo F, et al. Evaluation of smoking cessation intervention in patients with chronic diseases in smoking cessation clinics. Med (Baltimore). 2017;96:e7459-e.

9. Raosoft.com. Sample Size Calculator by Raosoft, Inc. 2004 [cited 2020 February 15]. Available from: http://www.raosoft.com/samplesize.html.

10. Nour Eldein H, Mansour NM, Mohamed SF. Knowledge, attitude and practice of family physicians regarding smoking cessation counseling in family practice centers, suez canal university, egypt. J Family Med Prim Care. 2013;2:159-63.

11. Scholz J, Portela LD, Abe TMO, Gaya PV, Santos VG, Ferreira C, et al. Cost-effectiveness analysis of smokingcessation treatment using electronic medical records in a cardiovascular hospital. Clin Trials Regul Sci Cardiol. 2016;14:1-3

12. Bassiony MM. Smoking in Saudi Arabia. Saudi Med J. 2009;30:876-81.

13. Al Nohair SF. Prevalence of smoking and its related behaviors and beliefs among secondary school students in riyadh, saudi arabia. Int J Health Sci (Qassim) 2011;5:51-7.

14. Jradi H, Al-Shehri A. Knowledge about tobacco smoking among medical students in Saudi Arabia: findings from three medical schools. J Epidemiol Glob Health. 2014;4:269-76.

15. Kujan O, Abuderman A, Azzegahiby S, Alenzi FQ, Idrees M. Assessing oral cancer knowledge among Saudi medical undergraduates. J Cancer Educ. 2013;28:717-21.

16. Kujan O, Alzoghaibi I, Azzeghaiby S, Altamimi MA, Tarakji B, Hanouneh S, et al. Knowledge and attitudes of Saudi dental undergraduates on oral cancer. J Cancer Educ. 2014;29:735-8.

17. Morse DE, Psoter WJ, Cleveland D, Cohen D, MohitTabatabai M, Kosis DL, et al. Smoking and drinking in relation to oral cancer and oral epithelial dysplasia. Cancer Causes Control. 2007;18:919-29.

18. Cornuz J, Humair J-P, Seematter L, Stoianov R, van Melle $\mathrm{G}$, Stalder H, et al. Efficacy of resident training in smoking cessation: a randomized, controlled trial of a program based on application of behavioral theory and practice with standardized patients. Ann Intern Med. 2002;136:429-37.

19. AlAteeq M, Alrashoud AM, Khair M, Salam M. Smoking cessation advice: the self-reported attitudes and practice of primary health care physicians in a military community, central Saudi Arabia. Patient Prefer Adherence. 2016;10:651-8.

20. Al-Turkstani AHM, Alkail BA, Hegazy AA, Asiri SI. Knowledge, attitude, and practice among primary healthcare physicians toward smoking cessation in Makkah, Saudi Arabia. Int J Med Sci Public Health. 2016;5:1-11.

21. Elmoghazy EH, Mostafa NS, Zaki LM, Amin WA. Effect of training and smoking status of physicians on smoking cessation practices in Egypt. Egypt J Chest Dis Tuberc. 2018;67:323. seeking behaviour among health professionals in Federal Medical Center, Abuja. Libr Philos Pract 2017;(1).

24. De Angelis G, Wells GA, Davies B, King J, Shallwani SM, McEwan J, et al. The use of social media among health professionals to facilitate chronic disease self-management with their patients: A systematic review. Digit Health 2018;4:2055207618771416. 
25. Semwal M, Whiting P, Bajpai R, Bajpai S, Kyaw BM, Tudor Car L. Digital Education for Health Professions on Smoking Cessation Management: Systematic Review by the Digital Health Education Collaboration. J Med Internet Res. 2019;21:e13000-e.

26. Romani M, Jawhar S, Shalak M, Antoun J. Waterpipe smoking cessation: knowledge, barriers, and practices of primary care physicians- a questionnaire-based crosssectional study. BMC Fam Pract. 2020;21:21.

27. Al-Amari E. Practice and attitude differences in physician cigarette use: A study of prevalence, physicians' role, and smoking policy awareness in Dubai, UAE: The University of Texas School of Public Health; 2011.

28. Peng D-Y, Zhou J-H, Chen H, Li R, Li C, Zhou H-Y, et al. Respiratory physicians' knowledge, attitude and practice of tobacco control and their smoking status in the city of Chongqing. Zhonghua Jie He He Hu Xi Za Zhi. 2013;36:283-7.

29. Asid E. The effect of physicians' smoking-related knowledge, attitude, and practices on their smoking-cessation counseling. Ateneo de Zamboanga University; 2010.

30. Hodgetts G, Broers T, Godwin M. Smoking behaviour, knowledge and attitudes among Family Medicine physicians and nurses in Bosnia and Herzegovina. BMC Fam Pract 2004;5:12.

31. Jradi H. Awareness, practices, and barriers regarding smoking cessation treatment among physicians in Saudi Arabia. J Addict Dis. 2017;36:53-9.

32. Williams JM, Miskimen T, Minsky S, Cooperman NA, Miller M, Budsock PD, et al. Increasing tobacco dependence treatment through continuing education training for behavioral health professionals. Psychiatr Serv. 2015;66:216.

How to cite this article: Alrufaidy AM, Alsubhi $O$, Khalifa R, Bakarman MA. Knowledge, attitude and barriers regarding smoking cessation counseling among primary health care physicians in Jeddah, 2019. $J$ Community Health Manag. 2020;7(1):3-13. 